University of Nebraska - Lincoln

DigitalCommons@University of Nebraska - Lincoln

1979

\title{
Turbulence Under Conditions of Sensible Heat Advection
}

R. P. Motha

S. B. Verma

University of Nebraska - Lincoln

N. J. Rosenberg

Follow this and additional works at: https://digitalcommons.unl.edu/natrespapers

Part of the Natural Resources and Conservation Commons, Natural Resources Management and Policy Commons, and the Other Environmental Sciences Commons

Motha, R. P.; Verma, S. B.; and Rosenberg, N. J., "Turbulence Under Conditions of Sensible Heat Advection" (1979). Papers in Natural Resources. 1191.

https://digitalcommons.unl.edu/natrespapers/1191

This Article is brought to you for free and open access by the Natural Resources, School of at DigitalCommons@University of Nebraska - Lincoln. It has been accepted for inclusion in Papers in Natural Resources by an authorized administrator of DigitalCommons@University of Nebraska - Lincoln. 
Reprinted from Journal of Applied Meteorology, Vol. 18, No. 4, April 1979

American Meteorological Society

Printed in U. S. A.

\title{
Turbulence under Conditions of Sensible Heat Advection ${ }^{1}$
}

\author{
Raymond P. Motha \\ Atmospheric Sciences Department and Center for Environmental Assessment Services; \\ University of Missouri, Columbia 65201 \\ Shashi B. Verma and Norman J. Rosenberg \\ Center for Agricullural Meteorology and Climatology, \\ University of Nebraska, Lincoln 68583 \\ (Manuscript received 5 June 1978, in final form 28 November 1978)
}

\begin{abstract}
Thermal inversions induced by regional advection dominate the daytime climate of the central Great Plains during much of the growing season. The influence of these inversions on the turbulent transfer of momentum, sensible heat and water vapor was investigated through detailed observations over an alfalfa crop. The standard deviations of fluctuations in vertical velocity, air temperature and vapor pressure as well as the correlation coefficients for momentum, sensible heat and water vapor were found to be similar under both advective and lapse conditions. Results indicate that turbulent mixing is effectively maintained under advective conditions to transport large quantities of sensible heat to the crop surface and water vapor away from it.
\end{abstract}

\section{Introduction}

Turbulence is responsible for the transport of momentum, sensible heat, water vapor, carbon dioxide and other entities in the atmospheric surface layer. Turbulent transfer is affected by atmospheric thermal stratification conditions. Under neutral conditions there is no buoyancy contribution since the temperature profile is characterized by the adiabatic lapse rate. Momentum transfer, on the other hand, continues as a result of mechanical production due to wind shear. However, air near the earth's surface is seldom in a state of neutral equilibrium. During the day when the temperature profile is normally lapse and stratification is unstable, thermal production of turbulence by buoyant forces augments mechanical production to enhance turbulent mixing. In contrast, when the atmosphere becomes stably stratified due to radiational cooling at night, mechanical production is counteracted by negative buoyant forces. As a result, the level of turbulent mixing is substantially diminished under nocturnal inversions. Wesely et al. (1970) point out that slow wave motion frequently occurs at night when the wind speed is low. Some transfer of momentum and heat flux occurs at night but at about one-tenth the daytime rate (Wesely et al., 1970).

${ }^{1}$ Published as Paper No. 5547, Journal Series, Nebraska Agricultural Experiment Station. The work reported was conducted under Regional Research Project 11-33 and Nebraska Agricultural Experiment Station Project 11-49.
The climate of the east central Great Plains is dominated by conditions of sensible heat advection during much of the summer growing season (Rosenberg, 1969; Rosenberg and Verma, 1978). These conditions are associated with relatively strong, warm and dry winds from arid regions primarily to the south and southwest. Under conditions of sensible heat advection, evapotranspiration exceeds the vertical energy flux of the net radiation-often by a factor as great as 2 . Such conditions are typical of late spring through summer in the east central Great Plains region (Rosenberg, 1969; Rosenberg and Verma, 1978).

Advective conditions occur when sensible heat flux is directed toward transpiring and evaporating surfaces. Fig. 1 shows air temperature profiles typical of sensible heat advection. The onset of sensible heat advection is indicated by the temperature profiles which became inverted throughout the day. The inverted profiles extend to at least $16 \mathrm{~m}$ above the ground indicating that the advection is not due only to local, small-scale phenomena but is, more likely, regional in character [for details see Brakke et al. (1978)].

Studies of turbulence characteristics in the atmospheric surface layer under non-advective (lapse and nocturnal) conditions have been reported by several investigators (e.g., Wesely et al., 1970; Haugen et al., 1971; McBean, 1971; Hogstrom and SmedmanHogstrom, 1974). The literature displays a lack of turbulence observations made over transpiring surfaces under conditions of sensible heat advection. 


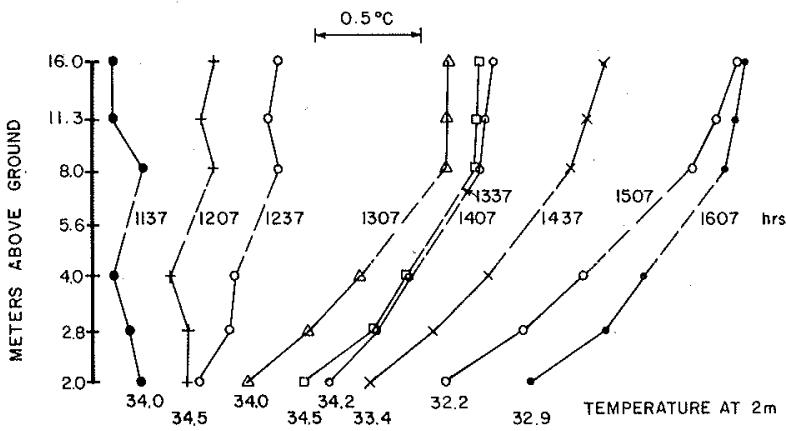

FIG. 1. Mean hourly air temperature profiles (typical) over an alfalfa crop at Mead, Nebraska.

In order to investigate the nature of turbulence under daytime (advection-induced) inversion conditions, measurements were made of wind velocity, temperature and vapor pressure fluctuations over a well-irrigated alfalfa crop. Appropriate turbulence statistics were computed under advective conditions and compared with statistics obtained under non-advective conditions.

\section{Methods}

The research was conducted at the University of Nebraska Agricultural Meteorology Research Laboratory at Mead, Nebraska $\left(41^{\circ} 09^{\prime} \mathrm{N} ; 96^{\circ} 30^{\prime} \mathrm{W} ; 354 \mathrm{~m}\right.$ MSL) during August 1976 and June and July 1977. Turbulent fluctuations of the three wind components $(U, V, W)$ were measured with Gill propeller anemometers $^{2}$ (Hicks, 1972; Gill, 1975). These anemometers were employed as a three-orthogonal-component $(U, V$, $W)$ anemometer to evaluate momentum flux and were used during the 1976 season in conjunction with a microbead thermistor ${ }^{3}$ for calculation of the sensible heat flux. During the 1977 season fine-wire dry-bulb and wet-bulb thermocouples ${ }^{4}$ were added to provide measurements of water vapor flux. All sensors were mounted $4.45 \mathrm{~m}$ above the soil surface. Concurrent mean wind speed and temperature profile data were obtained with cup anemometers and shielded copper constantan thermocouples on a $16 \mathrm{~m}$ micrometeorological tower. In addition, air temperature and vapor pressure profiles were measured at elevations up to $5.4 \mathrm{~m}$ with the "selfchecking" thermocouple psychrometers of Rosenberg and Brown (1974). Net radiation was measured with Swissteco net radiometers (type S-1). Soil heat flux was measured with heat flux plates buried about $4 \mathrm{~cm}$ deep in the soil. A computer-controlled data acquisition

${ }^{2}$ R. M. Young Co., Traverse City, Michigan (Model No. 27103).

${ }^{3}$ Victory Engineering Co., Springfield, N. J. . (VECO No. 51A401C).

${ }^{4}$ Tillman, J. E., 1973: Wet and dry-bulb thermocouple psychrometry. Atmospheric Technology, National Center for Atmospheric Research, No. 2, p. 77. [Performance details of the microbead thermistors and fine-wire thermocouple are given in Verma et al. (1979).] system, consisting of a mini-computer, analog-to-digital converters and a magnetic tape drive, was used to record all data. The fast-response turbulence signals were sampled 13 times per second while the slowresponse signals were sampled three times per minute. The fast-response analog signals were passed through a $5 \mathrm{~Hz} \mathrm{RC}$ low-pass filter.

The instruments were located at the north end of an experimental alfalfa field approximately $400 \mathrm{~m}$ in the $\mathrm{N}-\mathrm{S}$ direction and $105 \mathrm{~m}$ in the $\mathrm{E}-\mathrm{W}$ direction. The field was surrounded, except on the north, by alfalfa of the same age and cultivar. Observations were made only when the wind direction ranged from southeast to southwest. The propeller anemometers were calibrated in a wind tunnel at the University of Iowa, Iowa City. These calibrations were used to correct the anemometer data for its deviation from perfect cosine response. An iteration procedure, very similar to that of Horst (1972, 1973) was used for this purpose. Momentum, heat and water vapor fluxes were calculated using an eddy correlation technique. The instantaneous covariances were averaged over 45 min periods and appropriate constants were applied to yield estimates of momentum, heat and water vapor fluxes ${ }^{5}$ :

$$
\begin{gathered}
\tau=-\rho \overline{U^{\prime} W^{\prime}}, \\
H=-\rho C_{p} \overline{W^{\prime} T^{\prime}}, \\
L E=-\frac{L \epsilon}{P} \overline{\rho W^{\prime} e^{\prime}},
\end{gathered}
$$

where $\tau, H$ and $L E$ are the flux densities of momentum, sensible heat and latent heat, respectively, $\rho$ the air density, $C_{p}$ the specific heat of air at constant pressure, $L$ the latent heat of vaporization, $\epsilon$ the ratio of mole weights of water vapor and air, $U$ the horizontal wind component, $W$ the vertical wind component, $T$ the air temperature and $e$ the vapor pressure. The bar denotes a time average and the prime denotes an instantaneous deviation from the time-averaged quantity.

A characteristic velocity in the surface layer can be expressed in terms of the friction velocity $U_{*}$ given by

$$
U_{*}=\left(\begin{array}{l}
\tau \\
-
\end{array}\right)^{\frac{1}{2}} \text {. }
$$

Similarly, characteristic temperature and characteristic vapor pressure can be defined by

$$
\begin{aligned}
T_{*} & =\frac{H}{\rho C_{p} U_{*}}, \\
E_{*} & =\frac{L E}{(L \epsilon / P)_{\rho} U_{*}} .
\end{aligned}
$$

${ }_{5}^{5}$ The sign convention used here is such that all fluxes toward the crop or ground surface are positive and all away from the surface are negative. 
A moisture-corrected Monin-Obukhov stability parameter is defined as

$$
Z / L=-k Z g\left(\overline{W^{\prime} T_{v}^{\prime}}\right) / T_{v} U_{*}{ }^{3},
$$

where $g$ is the acceleration due to gravity, $k$ von Kármán's constant, $T_{v}$ the virtual temperature and $q$ the specific humidity at level $Z$, the height of observation [see McBean (1971) for details].

We recognize that the propeller anemometer does not respond satisfactorily to high-frequency fluctuations. The primary emphasis in this paper, however, is a qualitative comparison of turbulent statistics over an evapotranspiring crop surface under advective and non-advective conditions. We believe that by mounting the propeller anemometers at $4.45 \mathrm{~m}$ above ground and by applying the corrections described above we have minimized the loss in the flux carrying range.

\section{Results and discussion}

a. Sensible heat fux under advective and non-advective conditions

Meteorological conditions (including wind speed, air temperature, vapor pressure and net radiation) for a typical advective day (19 July 1977) and for a typical

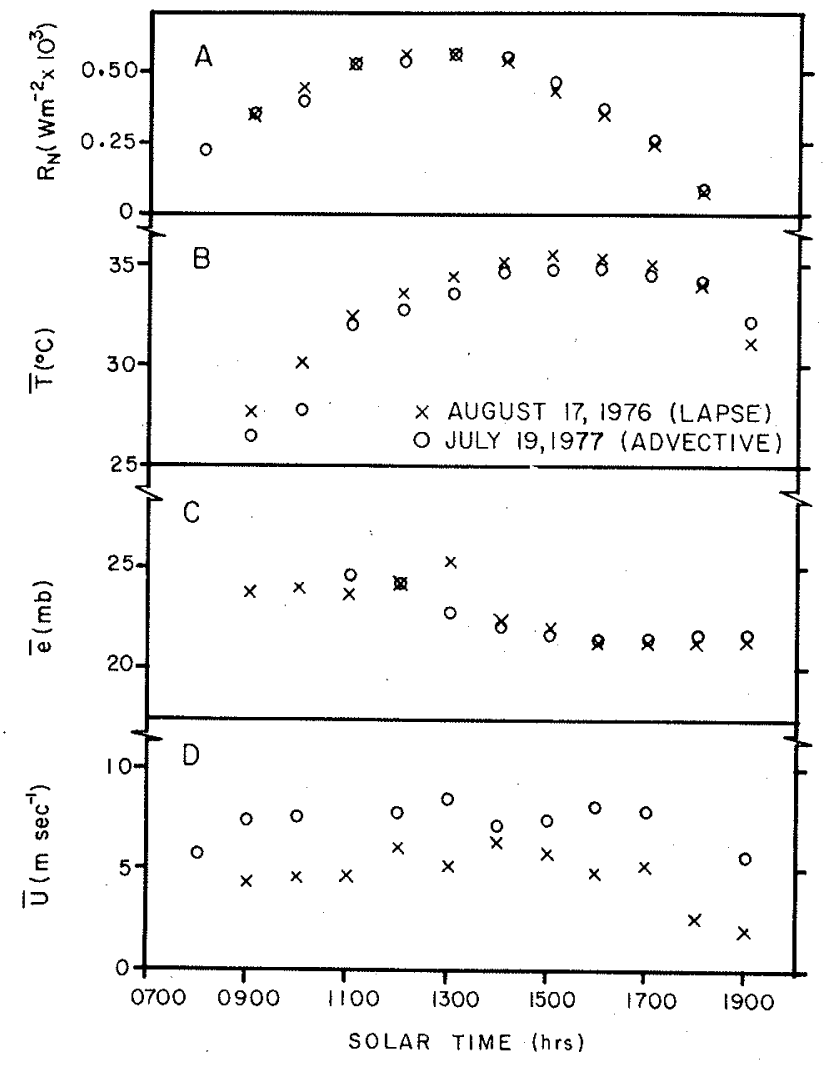

FIG. 2. Daily patterns of (A) net radiation, (B) air temperature, (C) vapor pressure and (D) wind speed on 17 August 1976 (lapse conditions) with stubble-like crop cover and 19 July 1977 (advective conditions) over alfalfa $0.5 \mathrm{~m}$ tall.

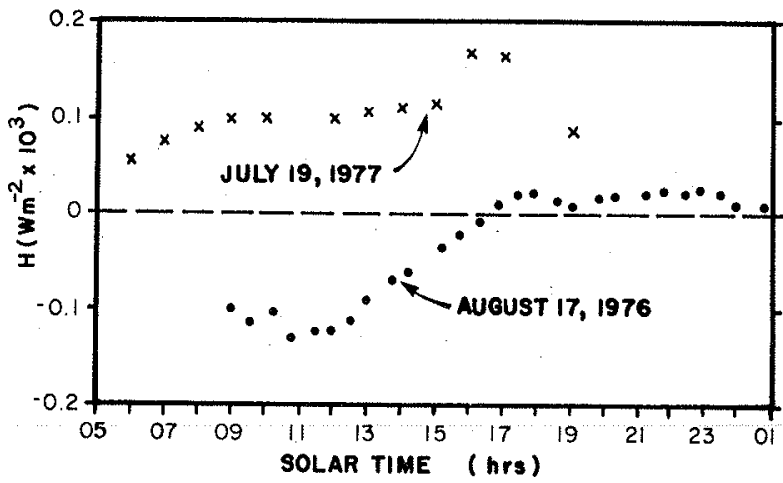

FIG. 3. Sensible heat fluxes observed on a typical advective day (19 July 1977) and a typical non advective day (17 August 1976) over an alfalfa crop at Mead, Nebraska.

non-advective day (17 August 1976) are compared in Fig. 2. Meteorological conditions were similar on these days. On 19 July the weather was dominated by strong regional advection of sensible heat. The alfalfa crop was about $50 \mathrm{~cm}$ tall and was vigorously transpiring since soil moisture was adequate. In contrast, on 17 August, lapse conditions prevailed throughout the day. The alfalfa had been harvested on 13 August and the crop was in a stubble-like condition.

Fig. 3 presents the diurnal pattern of sensible heat flux for 19 July 1977 and 17 August 1976. On 19 July advection-induced inversion conditions prevailed throughout the day (a positive heat flux indicates that the flow is directed toward the crop where it supplies energy for evapotranspiration). In contrast, on 17

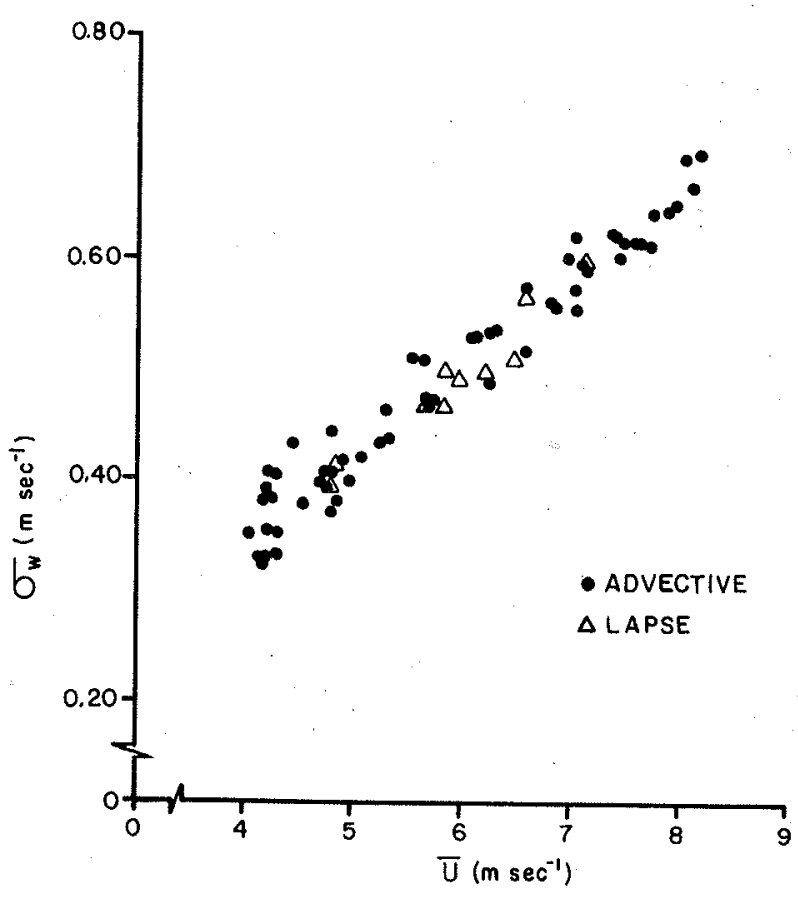

FIG. 4. Standard deviation of vertical velocity $\left(\sigma_{w}\right)$ as a function of mean wind speed $(\bar{U})$ at $4.45 \mathrm{~m}$ under daytime lapse and daytime advection-induced inversion conditions. 


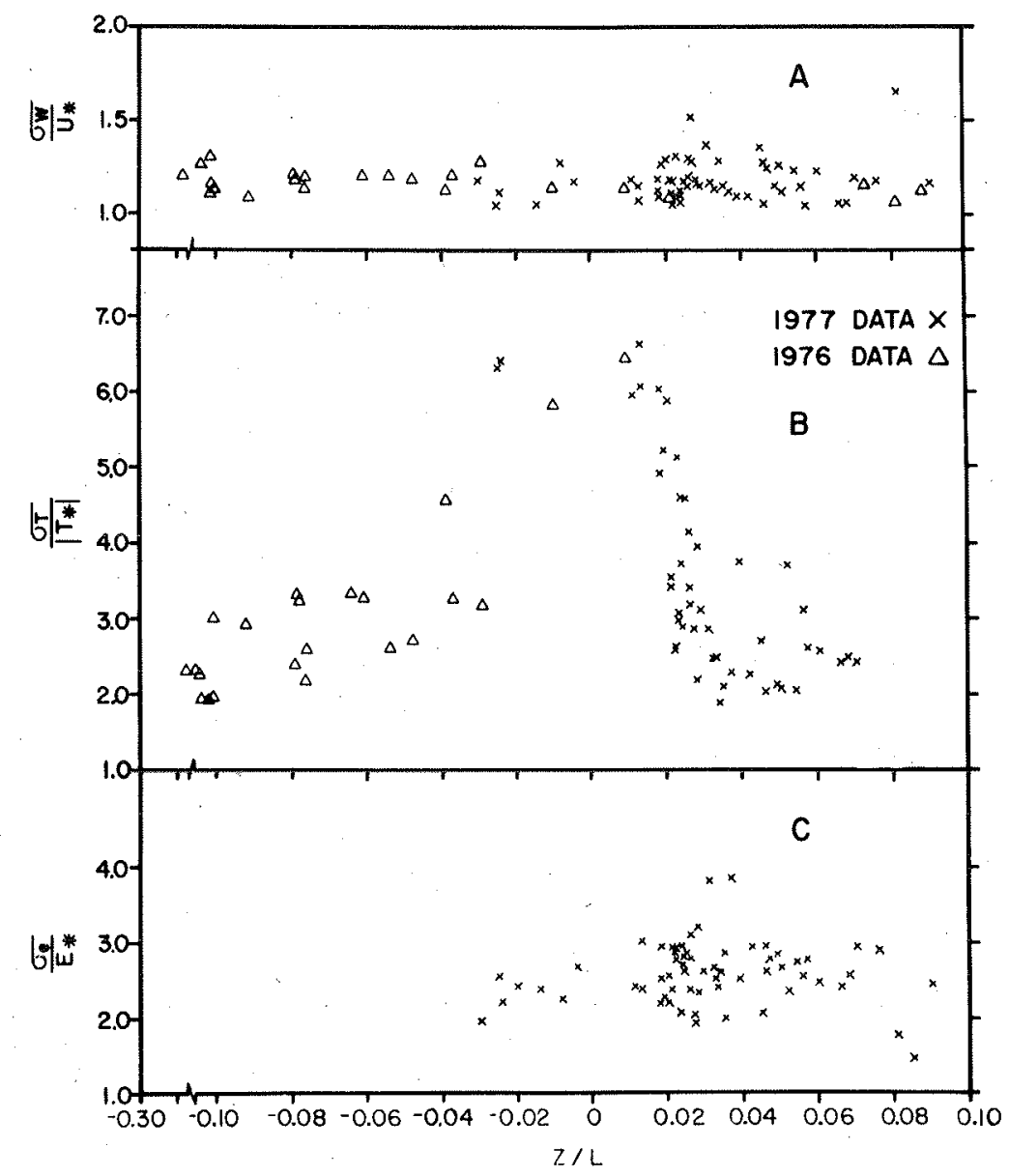

FIG. 5. Standard deviations of (A) vertical velocity, (B) temperature and (C) vapor pressure as functions of $Z / L$. Note change of scale of $Z / L$ for values $>|0.10|$.

August heat flux was negative until late afternoon indicating that heat was transported away from the surface. The magnitude of the sensible heat flux was similar on both days.

\section{b. Turbulent statistics as a function of Monin-Obukhov parameter $Z / L$}

\section{1) Turbulence InTEnsities}

The standard deviation of the vertical velocity fluctuations $\left(\sigma_{w}\right)$ is plotted as a function of the mean wind speed in Fig. 4 for daytime lapse and thermal inversions. The value of $\sigma_{w}$ is related almost linearly to the mean horizontal wind speed and this relationship does not appear dependent on thermal stratification.

Under lapse conditions typical values of $\sigma_{w}$ ranged from 0.35 to $0.50 \mathrm{~m} \mathrm{~s}^{-1}$. Under daytime inversion conditions $\sigma_{w}$ ranged from 0.50 to $0.66 \mathrm{~m} \mathrm{~s}^{-1}$. The standard deviations of temperature fluctuations $\left(\sigma_{T}\right)$ ranged from 0.14 to $0.57^{\circ} \mathrm{C}$ under lapse conditions and 0.33 to $0.53^{\circ} \mathrm{C}$ under daytime inversion conditions. Typical values for the standard deviations of the fluctuations in vapor pressure $\left(\sigma_{e}\right)$ during daytime inversion conditions ranged from 0.28 to $1.18 \mathrm{mb}$. The range of $\sigma_{w}, \sigma_{T}$ and $\sigma_{e}$ were similar to those reported by Kanemasu et al. (1979) for a $0.5 \mathrm{~m}$ high thick grass (roughness parameter $Z_{0} \approx 0.5 \mathrm{~m}$ ) and $Z / L \approx 0$.

Values of $\sigma$ are usually evaluated with respect to scaling parameters [Eqs. (4) $-(6)]$ determined from Monin-Obukhov similarity theory. The dependence of the three nondimensional $\sigma$ values (i.e., $\sigma_{w} / U_{*}, \sigma_{T} / T_{*}$ and $\sigma_{e} / E_{*}$ ) on $Z / L$ under daytime thermal inversions as well as lapse conditions was investigated.

The ratio $\sigma_{w} / U_{*}$ provides a measure of the relative intensity of turbulence. Fig. $5 \mathrm{~A}$ is a plot of $\sigma_{w} / U_{*}$ as a function of $Z / L$. Data for several days in 1976 and 1977 are included in this as well as following figures. The data are consistent across the year despite the fact that 1976 data were associated primarily with lapse conditions. Little difference between advective and nonadvective conditions in the values of $\sigma_{w} / U_{*}$ is seen in Fig. 5A. For $|Z / L|<0.09$, the average value of $\sigma_{w} / U_{*}$ is about 1.2 with some scatter in the data. 
Fig. 5B shows $\sigma_{T} / T_{*}$ as a function of $Z / L$. Note the cusp-like behavior near $Z / L \approx 0(-0.03<Z / L<0.03)$. This was due, primarily, to the fact that, during nearneutral periods, heat fluxes are negligibly small and a high degree of uncertainty in the resolution of $\sigma_{w} / T_{*}$ results. Such an effect has also been noted by Busch (1973). Although there is significant scatter in Fig. 5B, the values of $\sigma_{T} / T_{*}$ (for $|Z / L|>0.03$ ) are similar (ranging about 2.0 to 4.0 ) under both daytime lapse and inversion conditions.

A scaled parameter of the standard deviation of water vapor flux, $\sigma_{c} / E_{*}$, is plotted as a function of $Z / L$ in Fig. 5C. Although significant scatter in $\sigma_{e} / E_{*}$ occurs under advective conditions $(Z / L>0), \sigma_{e} / E_{*}$ ranged generally from 2.0 to 3.5 . For $Z / L<0, \sigma_{e} / E_{*}$ ranged from 2.0 to 2.7 . Although there are relatively few data points under lapse conditions, Fig. 5C suggests no significant difference in $\sigma_{e} / E_{*}$ between daytime lapse and thermal inversion conditions.
2) Correlation COETfictents of MOMEnTUM, SENSIBLE HEAT AND WATER VAPOR TRANSFERS

The correlation coefficients for momentum, sensible heat and water vapor are defined by

$$
\begin{aligned}
& r_{U W}=\frac{\overline{U^{\prime} W^{\prime}}}{\sigma_{U} \sigma_{W}}(\text { momentum }) \\
& r_{W T}=\frac{\overline{W^{\prime} T^{\prime}}}{\sigma_{W} \sigma_{T}} \text { (sensible heat) } \\
& r_{W e}=\frac{\overline{W^{\prime} e^{\prime}}}{\sigma_{W} \sigma_{e}} \text { (water vapor). }
\end{aligned}
$$

The correlation coefficients indicate the degree to which fluctuations of a particular property are associated with fluctuations in the vertical velocity. As such

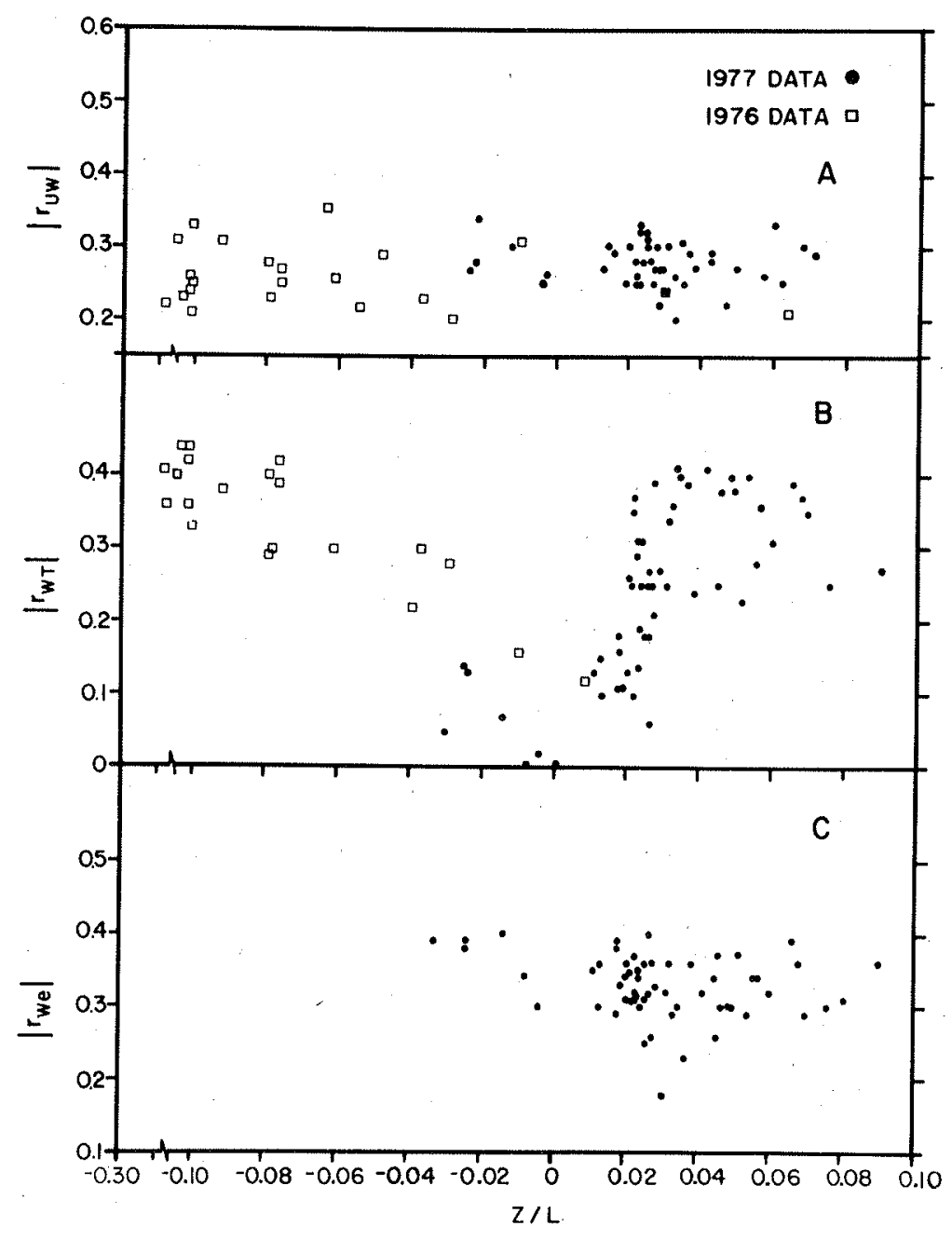

FIG. 6. Correlation coefficients of (A) momentum, (B) sensible heat and (C) water vapor as functions of $Z / L$. Note change of scale of $Z / L$ for values $>|0.10|$. 


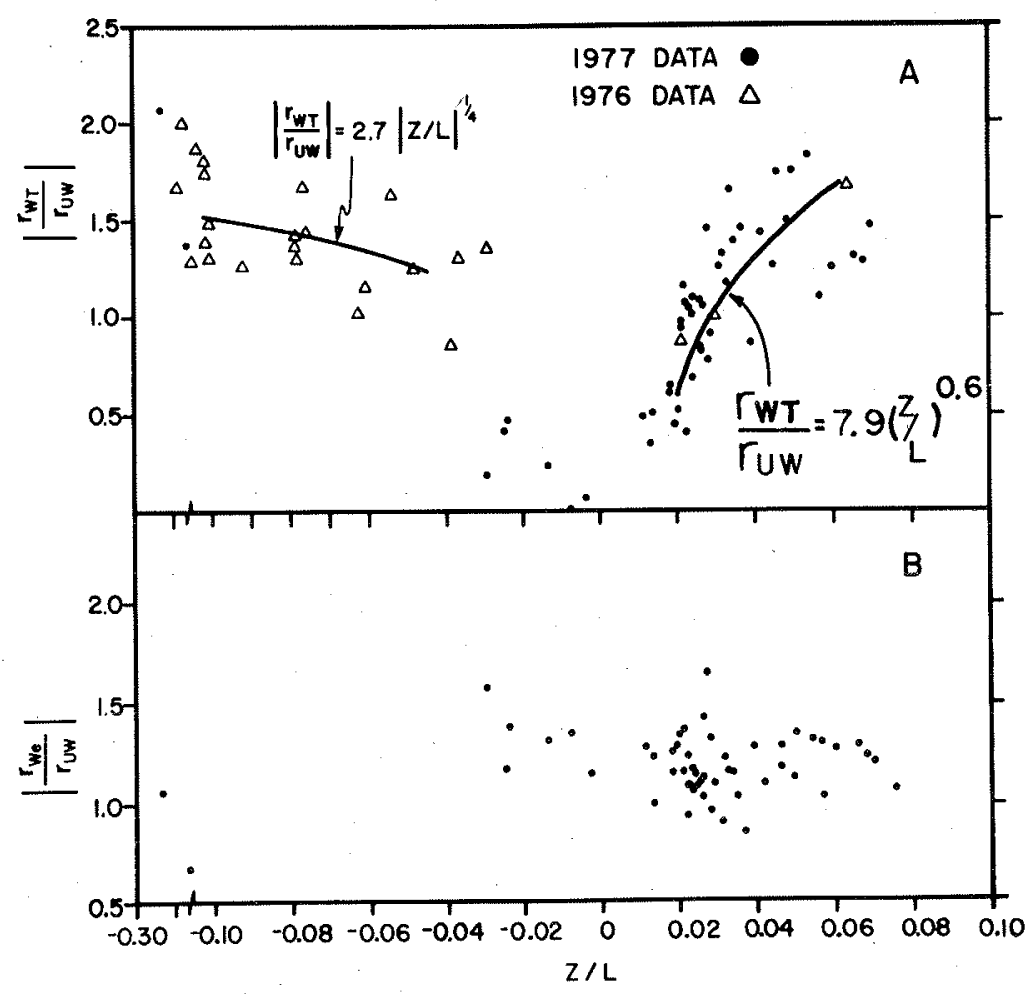

Frg. 7. Ratios of the correlation coefficients (A) sensible heat/momentum $\left(\left|r_{W T} / r_{U W}\right|\right)$ and (B) water vapor/momentum $\left(\left|r_{W} / r_{U W}\right|\right)$ as functions of $Z / L$. Note change of scale of $Z / L$ for values $>|0.10|$.

they provide a measure of the efficiency of the transport mechanisms involved (McBean, 1970).

Fig. 6A is a plot of the correlation coefficient for momentum, $\left|r_{U W}\right|$, as a function of $Z / L$ for both advective and lapse conditions. The average value of $\left|r_{U W}\right|$ is between 0.2 and 0.3 for both cases in the range of $Z / L$ between -0.2 and 0.07 .

A plot of $\left|r_{W T}\right|$ as a function of $Z / L$ is presented in Fig. 6B. $\left|r_{W T}\right|$ tends toward zero as $Z / L$ approaches zero since the heat flux approaches zero under neutral stability. It is interesting to note the relatively sharp increase in $r_{W T}$ under advective conditions for small $Z / L$ values which contrasts with the corresponding slow increase in $r_{W T}$ with increasing instability. Therefore, it appears that for small $Z / L$ (e.g., $|Z / L| \approx 0.03$ ), the efficiency of sensible heat transfer is relatively greater under advective than under lapse conditions.

The correlation coefficient for water vapor, $r_{W}$, is plotted as a function of $Z / L$ in Fig. 6C. Although there are relatively few data points under lapse conditions, the results for $r_{W e}$ appear to be similar to those for $r_{W T}$ and $r_{U W}$ in that no significant change in magnitudes between advective and non-advective cases are apparent.

\section{3) RELATIVE CORRELATION COEFFICIENTS}

The ratios of the correlation coefficients for momentum, heat and water vapor can provide some'insight into the relative efficiency of momentum, sensible heat and water vapor transfers. Figs. $7 \mathrm{~A}$ and $7 \mathrm{~B}$ present the ratios of $\left|r_{W} / r_{U W}\right|$ and $\left|r_{W e} / r_{U W}\right|$, respectively, as functions of $Z / L$. In Fig. $7 \mathrm{~A}\left|r_{W T} / r_{U W}\right|$ approaches zero as $Z / L$ approaches zero since the heat flux tends toward zero near $Z / L \approx 0$. With increasing instability, the ratio increases, indicating that the effects of buoyancy increase the transfer efficiency for sensible heat with respect to the momentum transfer. The best fit for our data for lapse conditions $(-0.20<Z / L<0)$ is $r_{W T} / r_{U W}=2.7|Z / L|^{\frac{1}{4}}$ which agrees well with values reported by McBean (1970) and McBean and Miyake (1972) $\left(r_{W T} / r_{U W}=3.0|Z / L|^{3}\right)$. The ratio also increases significantly with positive $Z / L$ during advective conditions [the best fit of data during advective conditions can be given by $\left.r_{W T} / r_{U W} \approx 7.9(Z / L)^{0.6}\right]$. This result is different from those of McBean (1970) and McBean and Miyake (1972) for positive $Z / L$ values (nonadvective conditions) since they did not observe any appreciable variation of $\left|r_{W T} / r_{U W}\right|$. This increase in $\left|r_{W T} / r_{U W}\right|$ for $Z / L>0$ appears to indicate that the relative efficiency of heat and momentum transfers is similar under daytime lapse and daytime inversion conditions. Fig. 7B shows $\left|r_{W_{e}} / r_{U W}\right|$ as a function of $Z / L$. This ratio generally ranges approximately from 1.0 to 1.4 for advective "conditions indicating that the transfer efficiency of water vapor is greater than that for momentum. 


\section{Summary}

The magnitudes of sensible heat flux are similar during both daytime lapse and daytime inversion conditions although the direction of flux, of course, differs. The standard deviations of fluctuations in vertical velocity, temperature and vapor pressure are also similar. Typical ranges of values for daytime lapse conditions and daytime inversion conditions, respectively, were $\sigma_{w}, 0.35$ to $0.45 \mathrm{~m} \mathrm{~s}^{-1}$ and 0.60 to $0.66 \mathrm{~m} \mathrm{~s}^{-1}$; and $\sigma_{T}, 0.14$ to $0.57^{\circ} \mathrm{C}$ and 0.33 to $0.53^{\circ} \mathrm{C}$. Typical values for $\sigma_{e}$ during daytime inversion conditions were 0.28 to $1.18 \mathrm{mb}$. When $\sigma_{w}, \sigma_{T}$ and $\sigma_{e}$ are adjusted with their appropriate scaling terms $\left(U_{*}, T_{*}\right.$ and $E_{*}$, respectively) and examined in light of similarity theory, the results indicate no significant change between daytime lapse and daytime inversion conditions in these nondimensional parameters.

The efficiency of turbulent transfer was examined in terms of the correlation coefficients for momentum, sensible heat and water vapor. The best fit for $r_{W} / r_{U W}$ data was found to be $\left|r_{W r} / r_{U W}\right| \approx 2.7|Z / L|^{1 /}$ for daytime lapse conditions and $r_{W} r / r_{U W} \approx 7.9(Z / L)^{0.6}$ for advective conditions. Our results appear to indicate that the overall relative efficiency of heat and momentum transfers is similar under daytime lapse and advective conditions.

The magnitudes of the turbulent fluctuations as well as the efficiencies of turbulent transfer under conditions of sensible heat advection are similar to those which prevail under lapse conditions. Turbulent transport remains effective under conditions of sensible heat advection.

Acknowledgments. This study was conducted with support of the Atmospheric Sciences Section, National Science Foundation, under Grant ATM 75-10000 A01. Our thanks to Messrs. Dale E. Sandin, Thomas Keber, James Hines and T. Grayson Redford, Jr., who assisted in the field observation and data computation, to Mrs. Roberta Sandhorst for stenographic work, to Mrs. Susan Cannon and Mr. Bruce Sandhorst for drafting, and to Drs. Blaine Blad and Albert Weiss for their review of this paper. We wish to thank Dr. John Kennedy and Mr. Dale Harris for their help in calibration of the propeller anemometers in the University of Iowa wind tunnel facility.

\section{REFERENCES}

Brakke, T. W., S. B. Verma and N. J. Rosenberg, 1978: Local and regional components of sensible heat advection. J. A p pl. Meleor., 17, 955-963.

Busch, N. E., 1973: Workshop on Micrometeorology. D. A. Haugen, Ed., Amer. Meteor. Soc., 1-66.

Gill, G. C., 1975: Development and use of the Gill UVW anemometer. Bound.-Layer Meleor., 8, 475-495.

Haugen, D. A., J. C. Kaimal and E. F. Bradley, 1971: An experimental study of Reynolds stress and heat flux in the atmospheric surface layer. Quart. J. Roy. Meteor. Soc., 97, 168-180.

Hicks, B. B., 1972: Propeller anemometers as sensors of atmospheric turbulence. Bound.-Layer Meteor., 3, 214-228.

Hogstrom, Ulf, and Ann-Sofi Smedman-Hogstrom, 1974: Turbulence mechanisms at an agricultural site. Bound.-Layer Meteor., 7, 373-389.

Horst, T. W., 1972: A computer algorithm for correcting noncosine response of the Gill anemometer. Pacific Northwest Labs., Annual Report for 1971 to the USAEC Div. of Biology and Medicine. Vol. II : Physical Science, Part I: Atmospheric Sciences, BNWL-1651-1, Battelle, Pacific Northwest Labs., Richland WA.

- 1973: Corrections for response errors in the three-component propeller anemometer. $J$. Appl. Meteor., 12, 716-725.

Kanemasu, E. T., M. L. Wesely, B. B. Hicks and J. L. Heilman, 1979: Techniques for calculating energy and mass fluxes. Modification of the Aerial Environment of Plants, ASAE Monogr., B. J. Barfield and J. F. Gerber, Eds. (in press).

Lumley, J. L., and H. Panofsky, 1964: The Structure of Aimospheric Turbulence. Wiley-Interscience, $231 \mathrm{pp}$.

McBean, G. A., 1970: The turbulent transfer mechanisms in the atmospheric surface layer. Ph.D. Thesis, University of British Columbia, 120 pp.

- - 1971: The variations of the statistics of wind, temperature and humidity fluctuations with stability. Bound-Layer Meteor., 1, 438-457.

_-, 1974: The turbulent transfer mechanisms: A time domain analysis. Quart. J. Roy. Meteor. Soc., 100, 53-66.

-, and M. Miyake, 1972: Turbulent transfer mechanisms in the atmospheric surface layer. Quart. J. Roy. Meteor. Soc. 98, 383-398.

Rosenberg, N. J., 1969: Seasonal patterns in evapotranspiration by irrigated alfalfa in the central Great Plains. Agron. J., 61, 879-886.

-_, and K. W. Brown, 1974: 'Self-checking' psychrometer system for gradient and profile determinations near the ground. Agric. Meieor, 13, 215-226.

_- and S. B. Verma, 1978: Extreme evapotranspiration by irrigated alfalfa: A consequence of the 1976 midwestern drought. $J$. Appl. Meteor., 17, 934-941.

Verma, S. B., R. P. Motha and N. J. Rosenberg, 1979: A comparison of temperature fluctuations measured by a microbead thermistor and a fine wire thermocouple over a crop surface. Agric. Meteor. (in press).

Wesely, M. L., G. W. Thurtell and C. B. Tanner, 1970: Eddy correlation measurements of sensible heat flux near the earth's surface. J. Appl. Meteor., 9, 45-50. 
